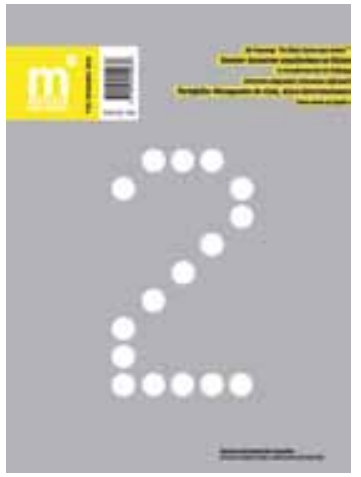

REVISTA MATERIA ARQUITECTURA N ${ }^{\circ} 02$

Escuela de Arquitectura, Arte y Diseño,

Universidad San Sebastián,

Ediciones Universidad San Sebastián

La edición número 02 de revista

MATERIA ARquITECTURA de la Universidad

San Sebastián, centra su interés en el

desarrollo de las ciudades chinas y

sus correspondientes transformaciones

arquitectónicas. Entre los temas que

aborda la revista, podemos encontrar las

modificaciones sufridas por Beijing, la

creación de identidad en nuevos pueblos de

Shangai y la relación entre lo urbano y lo rural en el contexto chino. En la sección de obras, se muestra un conjunto de proyectos que da cuenta de intervenciones que tienen como denominador común la pequeña escala.

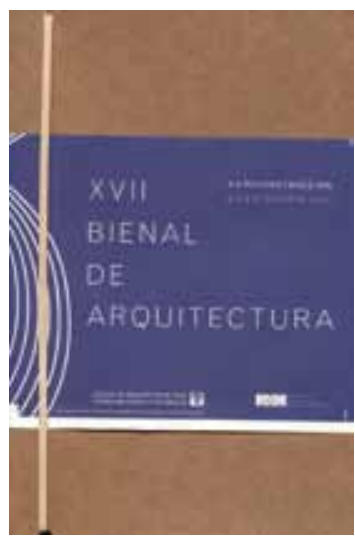

\section{CATÁLOGO XVI BIENAL}

\section{DE ARQUITECTURA}

Colegio de Arquitectos de Chile,

Fundación Espacio y Desarrollo,

8.8 reconstrucción / Bicentenario 2010

La publicación da cuenta de las reflexiones y obras seleccionadas por la reciente BIENAL DE ARQUITECTURA que se desarrolló en el Museo Histórico Militar. Un encuentro marcado por el terremoto y las propuestas de reconstrucción. Como novedad, en esta ocasión el catálogo no sólo publica proyectos de arquitectura, sino también una parte inicial dedicada a textos teóricos que reflexionan sobre la emergencia y reconstrucción.

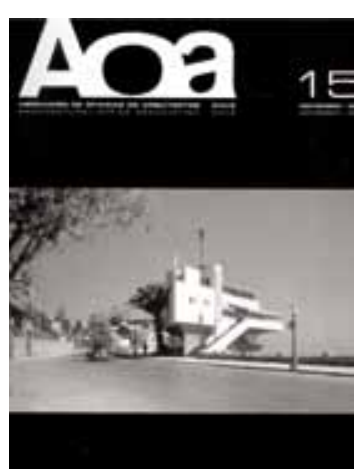

REVISTA AOA N ${ }^{\circ} 15$

Asociación de Oficinas de Arquitectos

La última edición de revista $A \circ A$, nos presenta un detallado artículo sobre la obra del arquitecto Roberto Dávila, autor fundamental de la arquitectura chilena de la primera mitad del siglo xx. En la sección de obras recientes, destacan el Centro Cultural Gabriela Mistral, el Centro Deportivo Chimkowe y el Edificio Block Social Nestlé Graneros, que entregan una muestra de la arquitectura reciente en nuestro país.

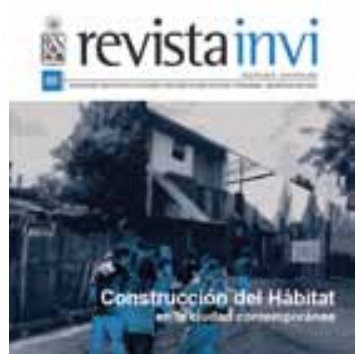

REVISTA INVI, VOL. 25 № 69

"Construcción del hábitat en la ciudad contemporánea

Instituto de la Vivienda,

Facultad de Arquitectura y Urbanismo, Universidad de Chile

La edición número 69 de la revista del Instituto de la Vivienda, aborda el desarrollo expansivo de las ciudades contemporáneas y los alcances que tal proceso tiene en la conformación del hábitat de sus ciudadanos. Entre los artículos que podemos encontrar, destaca una investigación sobre el caso del área metropolitana de Monterrey, México, un trabajo sobre nuevas formas de urbanización en Valparaíso y una reflexión sobre el concepto de «hábitat digno».

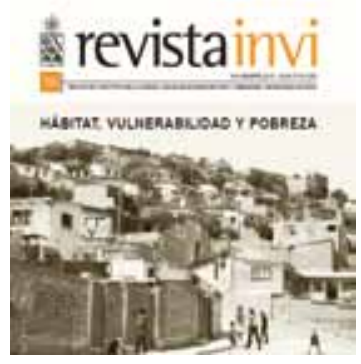

REVISTA INVI, VOL. $25 \mathrm{~N}^{\circ} 70$

"Hábitat, vulnerabilidad y pobreza» Instituto de la Vivienda,

Facultad de Arquitectura y Urbanismo, Universidad de Chile

El concepto de hábitat enfrentado a las condiciones de vulnerabilidad y pobreza, es el tema central de la última edición de revista INVI. En esta edición podemos encontrar los siguientes temas: un trabajo sobre las viviendas espontáneas en la ciudad de Lima, Perú; una investigación sobre el ordenamiento territorial y la relación entre los cambios climáticos y los climas urbanos, entre otros. Temas abordados con la profundidad habitual de la revista. 